\title{
Optimalisasi Penatalaksanaan Kegawatan di Ruang Kegawatdaruratan pada Era New Normal
}

\author{
${ }^{1}$ Yarwin Yari, ${ }^{2}$ Veronica Yeni Rahmawati, ${ }^{3}$ Ernawati, ${ }^{4}$ Fendy Yesayas, ${ }^{5}$ Ayu Lestari, ${ }^{6}$ Arizton Putra Jaya, \\ 7Eni Fatma Sari \\ ${ }^{1,9}$ Program Studi Diploma Tiga Keperawatan, Sekolah Tinggi Ilmu Kesehatan RS Husada Jakarta \\ Korespondensi: yarwin@stikesrshusada.ac.id
}

\begin{abstract}
Abstrak: Sejak COVID-19 pertama kali di temukan di Wuhan, menyebabkan RS rujukan COVID-19 menjadi "kewalahan" termasuk di Indonesia. Pada pasien terkonfirmasi COVID-19 atau pun pada pasien yang masih terduga COVID-19, tindakan Bantuan Hidup Dasar (BHD) tidak perlu ditunda. Namun, ada beberapa prinsip yang harus disesuaikan untuk menjaga keselamatan pasien dan pemberi bantuan. Tujuan kegiatan pengabdian pada masyarakat ini adalah meningkatkan pengetahuan dan wawasan peserta pada umumnya mengenai tata laksana kegawatdaruratan pada masa pandemic COVID-19. Metode dalam pelaksanaan kegiatan pengabdian kepada masyarakat ini terbagi dalam beberapa tahapan, yaitu pertama melakukan sosialisasi, melakukan webinar, dilanjutkan dengan FGD. Hasil dari kegiatan ini adalah terlihat peningkatan pengetahuan BHD pada perawat IGD sebelum dan sesudah mengikuti pelatihan. Pemberian pengetahuan dan pelatihan BHD secara daring terbukti efektif meningkatkan pengetahuan perawat IGD.
\end{abstract}

Kata Kunci : BHD, COVID-19, Pengabdian Masyarakat.

Abstract: Since COVID-19 was first discovered in Wuhan, it has caused COVID-19 referral hospitals to be "overwhelmed" including in Indonesia. In patients with confirmed COVID-19 or in patients with suspected COVID-19, the Basic Life Support (BHD) does not need to be postponed. However, there are some principles that must be adapted to keep patients and caregivers safe. The purpose of this community service activity is to increase the knowledge and insight of participants in general regarding emergency management during the COVID-19 pandemic. The method in implementing community service activities is divided into several stages, namely first conducting socialization, conducting webinars, followed by FGD. The result of this activity is that there is an increase in BHD knowledge among emergency room nurses before and after participating in the training. The provision of online BHD knowledge and training has proven to be effective in increasing the knowledge of emergency room nurses. Keywords: BHD, COVID-19, Community Service.

\section{PENDAHULUAN}

Kegawatdaruratan dapat terjadi kapan saja, dimana saja dan pada siapa saja. Upaya mengatasi kegawatdaruratan pada penyelamatan jiwa (life saving) dengan mempertimbangkan waktu, tantangannya adalah nyawa. Kecepatan pemberian pertolongan akan sangat berpengaruh kepada keselamatan jiwa pasien, atau dengan kata lain, apabila pertolongan terlambat diberikan akan berakibat kematian ${ }^{1}$.

Selama masa pandemi covid-19, situasi ruang Instalasi Gawat Darurat (IGD) ramai didatangi pasien dengan gejala yang mengarah pada covid-19. Banyak rumah sakit kewalahan untuk melayani pasien yang begitu banyak. Beberapa dari pasien bahkan merasa tidak diberi penanganan secepatnya. Namun, perlu diketahui bahwa dokter dan perawat diharuskan untuk mendahulukan pasien yang kondisinya paling gawat. Hal tersebut merupakan prosedur yang wajar dalam dunia tenaga kesehatan karena setiap IGD menganut sistem triase gawat darurat medis ${ }^{2}$.

Di Indonesia kasus COVID-19 pertama kali diumumkan pada tanggal 2 Maret 2020 sebanyak 2 kasus dan sampai saat ini kasus COVID-19 semakin hari semakin bertambah. Pada tanggal 22 April 2021 jumlah orang dengan kasus terkonfirmasi positif Covid-19 sebanyak 1.626 .812 jiwa, kasus sembuh 1.481.449 jiwa, dan kasus meninggal 44.172. Provinsi dengan kasus terkonfirmasi terbanyak adalah DKI

This is an open-access article under the CC BY 4.0

International License

(C) Idea Pengabdian Masyarakat (2021) 
Jakarta, Jawa Barat, dan Jawa Tengah. Meningkatnya jumlah kasus harian di Indonesia menyebabkan fasilitas kesehatan terutama RS rujukan COVID-19 menjadi kewalahan dengan banyaknya temuan kasus COVID-19 yang datang ke Instalasi Gawat Darurat (IGD), sementara kapasitas ruang isolasi di IGD terbatas.

Tenaga keperawatan merupakan salah satu tenaga kesehatan yang memegang peranan penting dalam meningkatkan derajat kesehatan dan merupakan tulang punggung di fasilitas pelayanan karena jumlahnya lebih banyak dibandingkan tenaga kesehatan lain. Perawat memiliki peran sebagai caregiver yang merupakan peran utama dimana perawat akan terlibat aktif selama 24 jam dalam memberikan asuhan keperawatan kepada pasien. Selain itu, perawat juga berperan sebagai edukator yang bertugas memberikan pendidikan kesehatan kepada pasien yang menjalani isolasi, keluarga, dan masyarakat umum $^{3}$.

Pada masa pandemik COVID-19, terutama untuk pasien-pasien terkonfirmasi COVID-19 atau pun pada pasien yang masih terduga COVID-19, tindakan Bantuan Hidup Dasar (BHD) tidak perlu ditunda, seperti layaknya pada pasien penyakit lainnya. Namun, ada beberapa prinsip yang harus disesuaikan untuk menjaga keselamatan pasien dan pemberi bantuan ${ }^{4}$.

Berdasarkan latar belakang tersebut maka dibutuhkan forum diskusi untuk saling membagikan pengalaman bagi mahasiswa, alumnus, dosen maupun tenaga kesehatan terkait update informasi keperawatan gawat darurat di era new normal. Dengan demikian STIKes RS Husada bermaksud mengadakan kegiatan pengabdian masyarakat keperawatan gawat darurat dengan tema "Optimalisasi Penatalaksanaan Kegawatan di Ruang Kegawatdaruratan Pada Masa Pandemi Covid-19".

\section{METODE}

Dalam pelaksanaan kegiatan pengabdian kepada masyarakat ini terbagi dalam beberapa tahapan, yaitu pertama melakukan sosialisasi kegiatan terlebih dahulu pada tanggal 03 Mei 2021, dilanjutkan dengan melakukan webinar pada hari pertama tanggal 30 Mei 2021 dengan menghadirkan 3 orang pembicara, pada hari kedua melakukan FGD paa tanggal 31 Mei 2021, dan pada hari terakhir melanjutkan FGD dengan menghadirkan pembicara serta melakukan evaluasi pada tanggal 01 April 2021.

Pada tahap pelaksanaan yang berlangsung selama 3 hari kami memilih 8 orang responden untuk dijadikan sampel, 8 orang responden ini sebelum mengikuti kegiatan webinar dan FGD mereka terlebih dahulu mengisi kuesioner dalam bentuk g-form terkait pelaksanaan BHD di masa pandemic, dan setelah mengikuti webinar dan FGD responden Kembali mengisi kuesioner.

\section{HASIL DAN PEMBAHASAN}

Tahap Persiapan

Persiapan dilakukan dengan menyampaikan kepada mitra baik dari Puskesmas dan Rumah Sakit apa yang akan dilakukan, kemudian Tim menyiapkan materi, serta menyiapkan bahan dan alat yang akan digunakan.

\section{Tahap Pelaksanaan}

Pada hari peratama yang di isi dengan kegiatan webinar, yang dihadiri oleh 500 orang peserta dari perawat rumah sakit, perawat puskesmas dan mahasiswa keperawatan dari beberapa kampus. Dalam acara webinar dihadiri tiga orang pembicara, yaitu pembicara peratama dr. Andy Wijaya, Sp.EM yang merupakan kepala IGD RS Husada dengan topik yang dibahas penatalaksanaan kegawatdaruratan di Ruang IGD pada era New Normal. Pemateri kedua Ns. Dally Rahman, M.Kep.,Sp.Kep.MB. yang 
merupakan kepala bidang keperawatan RS Andalas Padang, dengan topik yang dibahas yaitu peran perawat dalam memberikan asuhan keperawatan di Ruang critical care pada era new normal. Untuk pemateri ketiga Ns, Fendy Yesayas, M.Kep. yang merupakan dosen STIKes RS Husada dengan topik materi upaya pendampingan bagi pasien post COVID-19 pasca rawat inap ruang critical care.

Sebelum pemberian materi Bantuan Hidup Dasar (BHD) terlebih dahulu responden mengisi kuesioner pre test dan setelah mendapatkan materi selama 3 hari responden Kembali mengisi kuesioner post test dengan hasil dibawah ini:

Tabel 1 : Hasil Kuesioner

\begin{tabular}{cccccccc}
\hline No & Inisial & Umur & Instansi & Pendidikan & $\begin{array}{c}\text { Lama } \\
\text { Kerja }\end{array}$ & $\begin{array}{c}\text { PRE } \\
\text { TEST } \\
\text { BHD }\end{array}$ & $\begin{array}{c}\text { POST } \\
\text { TES } \\
\text { BHD }\end{array}$ \\
\hline 1 & M & 21 Tahun & RS Pantai Indah Kapuk & DIII & 6 bulan & 1 & 2 \\
\hline 2 & A & 22 Tahun & RS Pantai Indah Kapuk & DIII & 5 bulan & 1 & 2 \\
\hline 3 & H & 22 Tahun & RS Husada & DIII & 5 bulan & 1 & 2 \\
\hline 4 & E & 29 Tahun & PKM Sawah Besar & Ners & 3 bulan & 2 & 2 \\
\hline 5 & S & 21 Tahun & RS Husada & DIII & 5 bulan & 1 & 2 \\
\hline 6 & I & 28 Tahun & PKM Sawah Besar & DIII & 3 Tahun & 1 & 2 \\
\hline 7 & P & 30 Tahun & PKM Sawah Besar & DIII & 4 Tahun & 1 & 2 \\
\hline 8 & L & 32 Tahun & PKM Sawah Besar & DIII & 5 tahun & 1 & 2 \\
\hline
\end{tabular}

Keterangan : 1 : Pengetahuan BHD kurang baik 2 : Pengetahuan BHD baik

Dalam pengabdian kepada masyakat ini jumlah responden adalah 8 orang yang dimana semuanya merupakan perawat IGD, 4 orang sebagai perawat IGD Puskesmas Kecamatan Sawah Besar, 2 Orang Perawat IGD RS Husada dan 2 orang Perawat IGD RS Pantai Indah Kapuk. 7 orang responden dengan Pendidikan diploma tiga dan 1 orang dengan Pendidikan Ners, usia responden dari rentang usia 21 tahun sampai 32 tahun, lama kerja responden di instansi masing-masing paling lama adalah 5 tahun.

Dari table pre test terlihat bahwa dari 8 orang responden, 7 orang berada pada kriteria dengan pengetahuan BHD yang kurang baik, dan satu orang yang berada pada kriteria Baik. Rata-rata dari 7 responden dengan pengetahuan BHD kurang baik tidak mengetahui tata cara BHD pada masa pandemic COVID-19. Selain itu responden juga tidak memahami Langkah-langkah yang dilakukan Ketika menemukan pasien yang mengalami penurunan kesadaran di masa pandemic COVID-19. Responden belum memahami prinsip dalam melakukan BHD di masa pandemic serta belum memahami kapan pertolongan pertama pada masa pandemic COVID-19 dapat dilakukan dan kapang tidak dapat dilakukan

Setelah 8 orang responden selesai mengikuti materi terkait BHD selama 3 hari, responden Kembali diberikan kousioner post tes, dari hasil pengisian kuesioner dapat terlihat bahwa semua responden setelah diberikan materi BHD berada pada kategori dengan pengetahuan BHD baik, meskipun dalam pengisian kuesioner masi ada beberapa pertanyaan yang dijawab kurang tepat. 
Berdasarkan kuesioner yang di isi beberapa responden kurang tepat dalam menjawab pertanyaan terkait Langkah-langkah BHD di masa pandemic, hal ini diperkirakan terjadi karena saat menerima materi responden masi sibuk melakukan pelayanan, sehingga tidak bisa fokus dalam menerima materi yang diberikan.
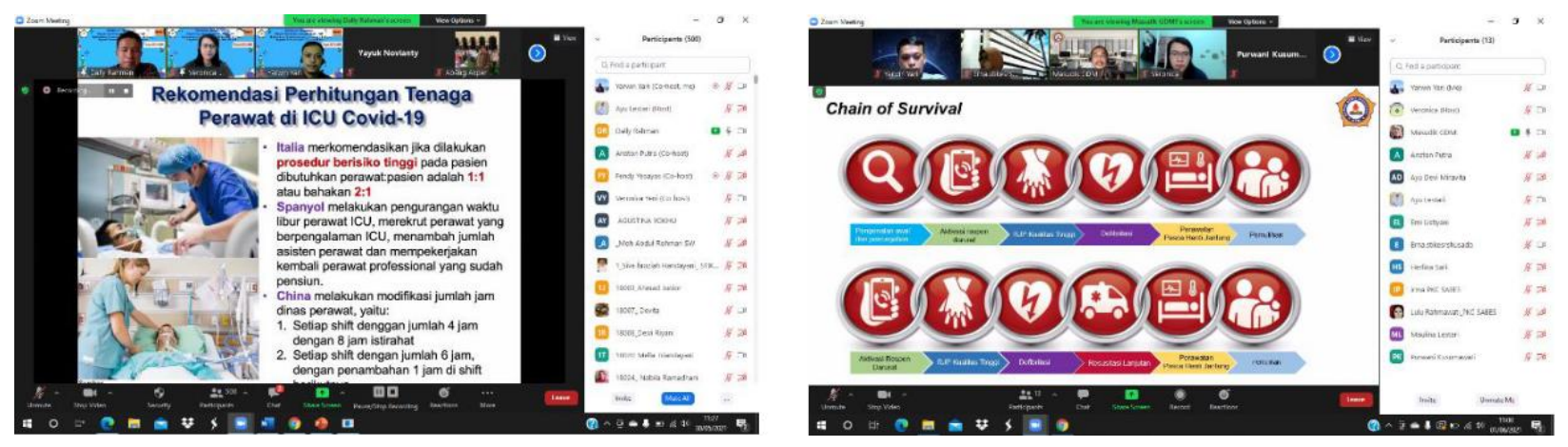

Gambar 1 dan 2 : Kegiatan Webinar dan FGD

Kegagalan dalam hal penanganan pasien gawat darurat umumnya disebabkan oleh ketidakmampuan mengenal risiko, keterlambatan rujukan, kurangnya sarana yang memadai, pengetahuan dan keterampilan tenaga medis, paramedis dalam mengenal keadaan risiko tinggi secara dini yang harus dilakukan secara efektif dan efisien ${ }^{5}$. BHD di masa pandemic COVID-19 merupakan salah satu hal yang penting dalam melakukan penanganan pasien gawat darurat, karna akan mempengaruhi dalam keberhasilan menyelamatkan pasien gawat darurat serta keselamatan penolong ${ }^{6}$.

Pengetahuan BHD dalam menanggulangi penderita gawat darurat di masa pandemic COVID-19 merupakan faktor yang sangat penting dalam menentukan keberhasilan pertolongan pasien. Kesalahan atau ketidaktepatan pemberian pertolongan pertama dapat menyebabkan kecacatan atau kematian penderita gawat darurat. Upaya yang harus dilakukan untuk meminimalkan angka kematian penderita gawat darurat di masa pandemic COVID-19 ini adalah dengan meningkatkan pengetahuan dalam melakukan BHD di masa pandemic ini ${ }^{7}$.

Rendahnya pengetahuan perawat IGD dalam melakukan BHD yang tentunya akan berdampak pada kualitas pelayanan, tentunya hal ini dipengaruhi oleh kurangnya pelatihan terkait penanganan pasien gawat darurat di masa pandemic COVID-19. Sejalan dengan pernyataan Nirmalasari ${ }^{8}$ bahwa pelatihan dan pemberian materi BHD dapat meningkatkan pengetahuan dan keterampilan seseora dalam penanganan pasien gawat darurat. Hal yang sama juga diungkapkan Irianto ${ }^{9}$ bahwa terjadi peningkatan Pengetahuan responden tentang cara melakukan bantuan hidup dasar yang baik dan benar setelah dilakukan pelatihan menggunakan video.

Berdasarkan hal tersebut, maka selama 3 hari 8 orang responden diberikan materi serta video terkait BHD dimasa pandemic COVID-19. Dan dari hasil penilaian yang dilakukan setelah semua peserta mengikuti kegiatan selama 3 hari, terdaat peningkatan pengetahuan pada peserta dalam melakukan BHD di masa pandemic COVID-19.

Dari table 5.1 table terlihat semua responden memiliki pengetahuan yang baik setelah dilakukan pelatihan BHD secara daring. Sejalan dengan hasil penelitian Lontoh ${ }^{10}$ yang mengatakan bahwa Sebagian besar responden mengalami peningkatan pengetahuan dari sebelum diberikan pelatihan dan sesudah

This is an open-access article under the CC BY 4.0 International License

(c) Idea Pengabdian Masyarakat (2021)

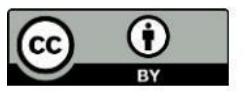
OPEN ACCESS 
diberikan pelatihan, penelitian lainya juga mendukung hal ini, Penyuluhan perlu dilakukan agar meningkatkan pengetahuan Masyarakat 11,12

Setelah dilakukan pelatihan selama 3 hari perawat merasakan sangat banyak manfaat utamanya dalam hal melakukan pertolongan peratama pada pasien gawat darurat di masa pandemic, perawat mengatakan hal ini sangat membantu mereka dalam merefresh ilmu mereka terkait penanganan pasien gawat darurat di masa pandemic COVID-19.

\section{KESIMPULAN}

Setelah responden mengikuti pelatihan selama tiga hari, sangat terlihat peningkatan pengetahuan BHD sebelum dan sesudah mengikuti pelatihan, setelah mengikuti pelatihan semua responden berada pada kategori pengetahuan BHD yang baik. Pemberian pengetahuan dan pelatihan BHD secara daring terbukti efektif meningkatkan pengetahuan perawat IGD.

\section{UCAPAN TERIMAKASIH}

Terimakasih kami ucapkan kepada Pihak Rumah Sakit Husada, Rumah Sakit Pantai Indah Kapuk dan Puskesmas Sawah Besar Jakarta Pusat dan seluruh orang yang terlibat pada pengabdian masyarakat ini.

\section{DAFTAR PUSTAKA}

1. Kusumaningrum BR, Kartika AW, Ulya I, Choiriyah M, Ningsih DK, Kartikasari E. Pelatihan Pertolongan Pertama pada Kegawatdaruratan di Sekolah Children Centre Brawijaya Smart School Malang. Int J Community Serv Learn. 2018;2(4):309-14.

2. Ose MI, Handayani F, Pujianto A, Sulfiana M, Ega A. Peningkatan Kualitas Caregiver Melalui Pelatihan Kegawatdaruratan dan Dasar di masa pandemic covid-19 Perawatan. 2021;3.

3. $\quad$ Nisa K. Pemutusan Rantai Penyebaran Infeksi Covid-19. 2020;2.

4. Ariani R, Muhammad A, Syahputra E. Ragam Penanganan dan Pencegahan COVID-19 di Rumah Sakit dan Klinik Primer. Medan; 2020.

5. Aswad Y, Luawo HP, Ali SM. Peningkatan Pengetahuan dan Keterampilan Karang Taruna melalui Pelatihan Bantuan Hidup Dasar (CPR) pada Masa Pandemi Covid-19 di Kecamatan Kota Utara, Kota Gorontalo. J Andidas. 2021;2(1):81-5.

6. Agamuthu P, Barasarathi J. Clinical waste management under COVID-19 scenario in Malaysia. Waste Manag Res. 2021;39(1_suppl):18-26.

7. Fatmawati A, Mawaddah N, Prafita Sari I, Studi Ilmu Keperawatan P, Tinggi Ilmu Kesehatan Majapahit S, Studi Profesi Ners P. Peningkatan Pengetahuan Bantuan Hidup Dasar Pada Kondisi Henti Jantung Di Luar Rumah Sakit Dan Resusitasi Jantung Paru Kepada Siswa Sma. JMM (Jurnal

Masy Mandiri) [Internet]. 2020;4(6):1176-84. Available from: http://journal.ummat.ac.id/index.php/jmm

8. Nirmalasari V, Winarti W. Pengaruh Pelatihan (Bhd) Terhadap Pengetahuan Dan Keterampilan Mahasiswa Kesehatan Masyarakat. J Keperawatan Widya Gantari Indones. 2020;4(2):115.

9. Irianto ID, Hadi S, Puspitasari I. Efektifitas Video Edukasi Bantuan Hidup Dasar Dalam Meningkatkan Pengetahuan Masyarakat Awam. J Keperawatan dan Kebidanan. 2020;12(1):29-33.

10. Lontoh C, Kiling M, Wongkar D. Pengaruh Pelatihan Teori Bantuan Hidup Dasar Terhadap Pengetahuan Resusitasi Jantung Paru Siswa-Siswi Sma Negeri 1 Toili. J Keperawatan UNSRAT. 2013;1(1):111914.

11. Amir H, Taqiyah Y. Pengaruh covid-19 kepada masyarakat. Pros Has Pengabdi Masy Tahun 2021. 2021;1-5. 
12. Amir H, Agus AI, Bima MIM, As'ad I, Hafid MF, Ashar JR, Zainal AQ, Jihad A, Musda GH. Penerapan 3M dalam Mencegah Penularan Covid-19 di Desa Lonjoboko Kabupaten Gowa. IPM [Internet]. 2021Jun.26 [cited 2021Sep.25];1(1):1-4. Available from: https://ideapengabdianmasyarakat.ideajournal.id/index.php/ipm/article/view/1 